\title{
CAE Modeling of Hot Stamping Tool Wear
}

\author{
A. Chernov ${ }^{1, *}, Y u$. Korobov ${ }^{1,2}$, and E. Raskatov ${ }^{2}$ \\ ${ }^{1}$ M.N. Mikheev Institute of Metal Physics of the Ural Branch of the Russian Academy of Sciences, \\ Russia, Yekaterinburg \\ ${ }^{2}$ Ural Federal University named after the first President of Russia B. N. Yeltsin, Russia, Yekaterinburg
}

\begin{abstract}
To assess the wear of the hot stamping tool, a model of punch deformation under the influence of thermal and mechanical loads was developed. The shape and relative position of the punch and die were designed to localize maximum contact loads at a predetermined location. It was assumed that the punch wear is caused by a removal of the surface metal layer, due to decreasing its mechanical strength during hot plastic deformation. Simulation was performed by the finite element method in the Deform software package. A temperature field and wear pattern in the contact zone were calculated. With respect to the loads typical for hot forging railway wheels, the comparison showed that the wear in a numerical experiment is of the same level as the actual value of wear.
\end{abstract}

\section{Intoduction}

Hot dies are subjected to heavy wear, for example, when hot stamping railway wheels, wear exceeds $0.2 \mathrm{~mm}$ per 1000 cycles [1]. The development of methods to increase their resource requires an assessment of their wear when changing the die material, as well as thermal and mechanical loads. Carrying out a full-scale experiment is notable for high costs. The laboratory loading technique [2] allows to reproduce the operating conditions of dies on small samples. Finite element simulation thermal fields and the stress-strain state in hightemperature loading in Deform package [3] may drastically reduce the amount of experimental work. The object of this study is to simulate the tool wear under typical conditions for hot die.

\section{Methodology}

Research equipment includes (refer with: Fig. 1): 1 - billet, 2 - bottom insert, 3 - end stop, 4 - bottom stop, 5 - pin and 6 - punch. Billet 1 is an analogue of the part subjected to hot stamping. It is pressed onto the tooth of the bottom insert 2 , which is an analog of the die. A groove in the billet is caused by the moving plunger 6 which is indicated by a dotted line. The groove height is bounded by the horizontal surface of the end stopper 3 and do not exceed $9 \mathrm{~mm}$. The end surface of the end stopper 3 prevents a longitudinal movement of the billet 1 at the loading time.

\footnotetext{
*Corresponding author: Alexeychernov65@gmail.com
} 
Fig. 1. Equipment diagram

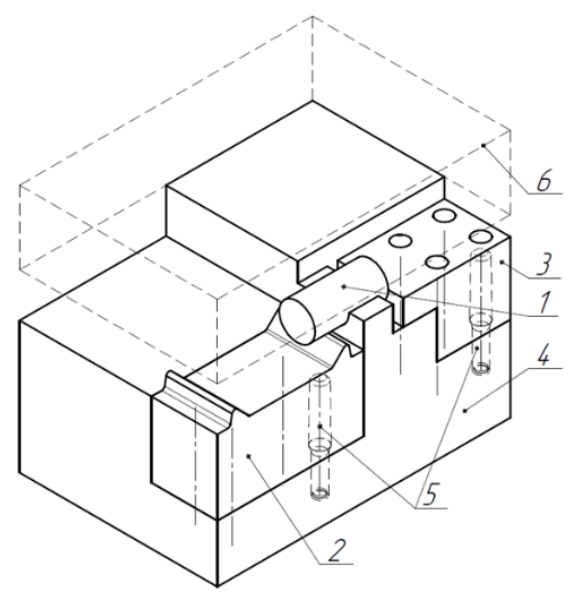

The lower die insert 2 is made of tool steel 5XHM, which is typical for die tooling.

As a billet material steel $60 \Gamma$ was used. It is a typical steel for railway wheels. The steel parts subjected to hot stamping and the dies are preliminary heated up to $800^{\circ} \mathrm{C}$ and $300^{\circ} \mathrm{C}$ respectively [1]. Accordingly, the thermophysical characteristics of the steels are presented in a table 1.

Table 1. Thermal characteristics of the used steels [4-6]

\begin{tabular}{|c|c|c|c|c|c|}
\hline $\begin{array}{l}\text { Density, } \\
{\left[\mathrm{kg} / \mathrm{m}^{3}\right]}\end{array}$ & $\begin{array}{c}\text { Thermal } \\
\text { conductivity, } \\
{\left[\mathrm{W} /\left(\mathrm{m} \times{ }^{\circ} \mathrm{C}\right)\right]}\end{array}$ & $\begin{array}{c}\text { Heat } \\
\text { capacity, } \\
{\left[\mathrm{J} / \mathrm{kg} \times{ }^{\circ} \mathrm{C}\right]}\end{array}$ & $\begin{array}{c}\text { Tensile } \\
\text { strength, } \\
{[\mathrm{MPa}]}\end{array}$ & \multicolumn{2}{|c|}{ Elastic modulus, [MPa] } \\
\hline \multicolumn{4}{|c|}{ At room temperature } & At room temperature & At $800^{\circ} \mathrm{C}$ \\
\hline \multicolumn{6}{|c|}{ steel 5XHM } \\
\hline 7800 & 38 & 500 & 1500 & 203000 & 132000 \\
\hline \multicolumn{6}{|c|}{ steel $60 \Gamma$} \\
\hline 7800 & 38 & 483 & 700 & 204000 & 174000 \\
\hline
\end{tabular}

Sample loading (refer with: Fig. 2) causes mechanical and thermal stresses.

To carry out the simulation, it was necessary to reveal the distribution of thermal fields in time and stresses of deformed states in a cylindrical body (sample) and on a protruding tooth of a hot wear-resistant die (tooling). In each cycle, a load of $1000 \mathrm{kN}$ is applied, the applied load time is $60 \mathrm{~s}$, the load speed is $0.2 \mathrm{~m} / \mathrm{s}$, the temperature of the billet is $900{ }^{\circ} \mathrm{C}$, the temperature of the bottom insert is $300{ }^{\circ} \mathrm{C}$.

The simulation was performed in Deform 3D software package, a specialized software package for modeling manufacturing processes of metal forming and heat treatment.

In the first step of calculation, it is assumed that each tooth is heated is in the form of an isosceles triangle. 
Fig. 2. Sample loading scheme

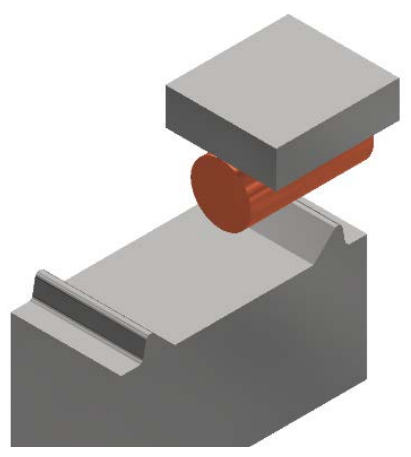

\section{Carrying out CAE-modeling of the stress-strain state of the body}

A computational grid has been generated using the triangle finite element (refer with: fig. 3 ). As initial conditions entered thermophysical characteristics of the material (refer with: table 1).

The following algorithm has been incorporated in this model. Loading with a billet leads to the occurrence of thermal and mechanical stresses in the tooth. When heated, the tensile strength of the material of the tooth is reduced and a part of the material during deformation is removed. A total tooth wear is equal to material removed during all cycles of loading.

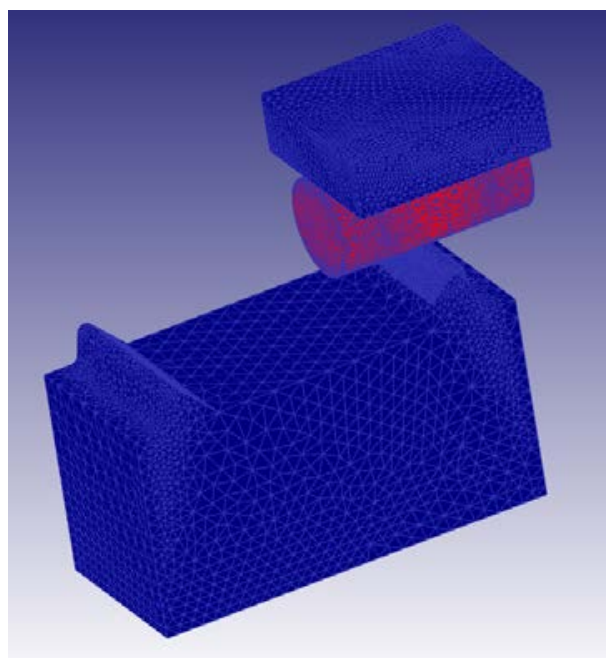

Fig. 3. Calculated model

\section{Results and discussion}

The calculated thermal field in the tooth at the end of the cycle is shown in Fig. 4.

The strength and modulus of elasticity of the tooth material in the contact area changes in accordance with the thermal field. The material of the tooth pulls off the surface due to friction (refer with: fig. 5) which causes wear of the tooth. Accepted coefficient of friction 0.28 corresponds to hot forging a low carbon steel in the range of $1000-1200{ }^{\circ} \mathrm{C}$ with graphite as a lubricant (refer with: fig. 5). 


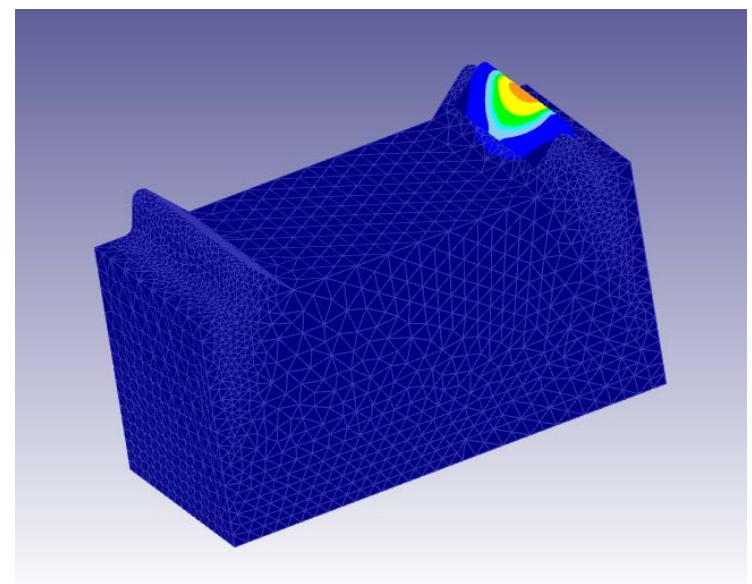

Fig. 4. Temperature field on the tooth surface in the contact zone with the workpiece

The distribution of wear depth on the tooth. The wear is in is in the range of $0.07-0.5 \mathrm{~mm}$ per 1000 cycles. This correlates satisfactorily with experimental data for railway wheel stamping, according to which the mean wear is about $0.2 \mathrm{~mm}$ [6].

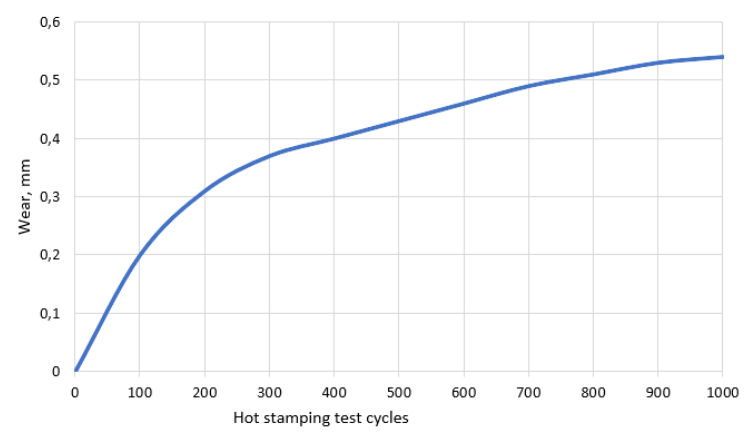

Fig. 5. A view of a calculated wear

\section{Conclusion}

With regard to laboratory samples that reproduce the operating conditions of hot dies, we simulated the wear of surfaces exposed to thermal and mechanical stress. The calculated depth of die wear at 1000 loading cycles was $0.54 \mathrm{~mm}$, which corresponds to the level of die wear applying to railway wheel stamping.

The work was done within state assignments from FASO Russia for IMP UB RAS on the subject № AAAA-A19-119070490049-8 and it was supported by FASIE grant (project IRA-SME № 58674). The authors are grateful to A. Okulov for help in developing the test methodology.

\section{References}

1. A.V. Kushnarev, Development of scientific foundations and implementation of modern technology for the production of railway wheels with high performance technology characteristics: doctoral thesis, Yekaterinburg, 2014. 
2. J. Marashi, E. Yakushina, P. Xirouchakis, R. Zante, J. Foster, An evaluation of H13 tool steel deformation in hot forging conditions, J. Mater Process Technol, 246 (2017) 276284.

3. V.S. Parshin, A practical guide to the Deform-3D software package: textbook manual, Ural Publishing House, Federal University, Yekaterinburg, 2010.

4. A.V. Tretyakov, Mechanical properties of metals and alloys during pressure treatment, Metallurgy, Moscow, 1973.

5. E.I. Semenov, Forging and stamping: Handbook in 4 volumes / Vol. 1 Materials and heating. Equipment. Forging, Mechanical Engineering, Moscow, 1985.

6. V.V. Kunilovsky, V.K. Krutikov, Cast dies for hot volumetric deformation, Mechanical engineering, Leningrad, 1987. 